\title{
1 Optimized FRP Wrapping Schemes for Circular Concrete Columns under
}

\section{Axial Compression}

\section{Abstract}

This study investigates the behavior and failure modes of fiber-reinforced-polymer (FRP) confined concrete wrapped with different FRP schemes, including fully wrapped, partially wrapped and non-uniformly wrapped concrete cylinders. By using the same amount of FRP, this study proposes a new wrapping scheme that provides a higher compressive strength and strain for FRP-confined concrete, in comparison with conventional fully wrapping schemes.

A total of thirty three specimens were cast and tested, with three of these specimens acting as reference specimens and the remaining specimens wrapped with different types of FRP (CFRP and GFRP) by different wrapping schemes. For specimens that belong to the descending branch type, the partially wrapped specimens had a lower compressive strength but a higher axial strain as compared to the corresponding fully wrapped specimens. In addition, the non-uniformly wrapped specimens achieved both a higher compressive strength and axial strain in comparison with the fully wrapped specimens. Furthermore, the partially wrapping scheme changes the failure modes of the specimens and the angle of the failure surface. A new equation that can be used to predict the axial strain of concrete cylinders wrapped partially with FRP is proposed.

CE Database subject headings: Fiber Reinforced Polymer; Confinement; Concrete columns;

21 Strain; Stress-strain relation; Concrete; Cylinders.

${ }^{1}$ Postdoctoral Research Associate, School of Civil and Mechanical Engineering, Curtin University, Kent Street, Bentley, WA 6102, Australia; Formerly, PhD Scholar, School of Civil, Mining and Environmental Engineering, University of Wollongong, Wollongong, NSW 2522, Australia. Email: thong.pham@curtin.edu.au

${ }^{2}$ Associate Professor, School of Civil, Mining and Environmental Engineering, University of Wollongong, Wollongong, NSW 2522, Australia (corresponding author). Email: mhadi@uow.edu.au

${ }^{3}$ Ph.D. Candidate, School of Civil, Mining and Environmental Engineering, University of Wollongong, Wollongong, NSW 2522, Australia. Email: jy201@uowmail.edu.au 
Fiber Reinforced Polymer (FRP) has been commonly used to strengthen existing reinforced concrete (RC) columns in recent years. In such cases, FRP is a confining material for concrete in which the confinement effect leads to increase in the strength and ductility of columns. In early experimental studies that focused on retrofitting RC columns with FRP, the columns were usually wrapped fully with FRP sheets. This wrapping scheme provides continuous confinement to the columns along their longitudinal axes. Most of the studies in the literature focus only on columns fully wrapped with FRP (Chaallal et al. 2003; Hadi et al. 2013; Pham et al. 2013; Pham and Hadi 2014a; Smith et al. 2010). In addition, columns wrapped partially with FRP have also been proven to show increases in strength and ductility, as compared to equivalent unconfined columns (Colomb et al. 2008; Maaddawy 2009; Turgay et al. 2010). However, there is no study that makes a comparison of the confinement efficacy between partially and fully wrapping schemes in terms of optimization of the FRP amount. In addition, the progressive failure of those specimens has not been extensively studied. Therefore, it is necessary to investigate the confinement efficacy and failure mechanisms of columns partially wrapped versus columns fully wrapped with FRP.

In addition, the available design guidelines for columns wrapped with FRP (ACI 440.2R-08 2008; fib 2001; TR 55 2012) are utilized to estimate the capacities of partially FRP-wrapped specimens. Among these studies, ACI-440.2R (2008) and technical report TR 55 (2012) do not provide information about the confinement effect of concrete columns partially wrapped with FRP. Meanwhile, fib (2001) suggests a reduction factor to take into account the effect of partial wrapping columns. The study by fib (2001) adopts an assumption proposed by Mander et al. (1988) for the confinement effect of steel ties in RC columns to analyze the efficacy of FRP partially wrapped columns. Therefore, there has been a lack of theoretical and 
experimental works about partial FRP-confined concrete. For this reason, an experimental program was developed in this study to compare the confinement efficacy of FRP partially wrapped columns as compared to FRP fully wrapped columns. The same amount of FRP was wrapped onto identical concrete columns by different wrapping schemes to achieve an optimized wrapping design.

\section{Confinement Mechanism}

\section{Fully Wrapped Columns}

In the literature, the term "FRP confined concrete" is understood automatically as concrete wrapped fully with FRP. When a circular concrete column is horizontally wrapped with FRP around its perimeter, the whole column is confined by the lateral pressure exerted from the FRP jackets as shown in Fig. 1a. Many studies have been carried out to investigate the behaviors and estimate the capacities of columns wrapped fully with FRP (De Luca and Nanni 2011; Lam and Teng 2003; Pham and Hadi 2014b; Pham and Hadi 2014c; Teng et al. 2009; Toutanji 1999; Wu and Zhou 2010). The confining pressure is assumed to be uniform in the cross section and along the axial axis of the circular columns. Among the existing studies, the model proposed by Lam and Teng (2003) is adopted in this study to calculate the compressive strength for columns wrapped fully with FRP as follows:

$$
\frac{f_{c c}^{\prime}}{f_{c o}^{\prime}}=1+3.3 \frac{f_{l}}{f_{c o}^{\prime}}
$$

where $f_{c c}$ ' and $f_{c o}$ ' are respectively the compressive strength of confined concrete and unconfined concrete, and $f_{l}$ is the effective confining pressure as follows:

$$
f_{l}=\frac{2 E_{f} \varepsilon_{f e} t}{D}
$$


where $E_{f}$ is the elastic modulus of FRP, $t$ is the nominal thickness of FRP jacket, $D$ is the diameter of the column section, and $\varepsilon_{f e}$ is the actual rupture strain of FRP in the hoop direction. The model by Lam and Teng (2003) is chosen because it provides a reasonable accuracy with a very simple form. The simplicity of the model by Lam and Teng (2003) is utilized to establish a new and simple strain model, which is presented in the sections below. The strain model proposed by Pham and Hadi (2013) is adopted to calculate the compressive axial strain of confined concrete as follows:

$$
\varepsilon_{c c}=\varepsilon_{c o}+\frac{2 k t f_{f e} \varepsilon_{f e}}{D f_{c o}^{\prime}+3.3 t f_{f e}}
$$

where $\varepsilon_{c c}$ is the ultimate axial strain of confined concrete, $\varepsilon_{c o}$ is the axial strain at the peak stress of unconfined concrete, $k=7.6$ is the proportion factor, and $f_{f e}$ is the actual rupture strength of FRP.

\section{Partially Wrapped Columns}

As mentioned above, concrete columns wrapped partially with FRP have been experimentally verified to increase their strength and ductility. Concrete columns partially wrapped with FRP are less efficient in nature than fully wrapped columns as both confined and unconfined zones exist (Fig. 1b). An approach similar to the one proposed by Sheikh and Uzumeri (1980) is adopted to determine the effective confining pressure on the concrete core. The effective confining pressure is assumed to be exerted effectively on the part of the concrete core where the confining pressure has fully developed due to the arching action as shown in Fig. 1b. The arching effect is assumed to be described by a second-degree parabola with initial slope of $45^{0}$. In such a case, a confinement effective coefficient $\left(k_{e}\right)$ is introduced to take the partial wrapping into account as follows: 


$$
k_{e}=\frac{A_{e}}{A_{c}}=\left(1-\frac{s}{2 D}\right)^{2}
$$

where $A_{e}$ and $A_{c}$ are respectively the area of effectively confined concrete core and the crosssectional area, and $s$ is the clear spacing between two FRP bands. Consequently, the compressive strength of concrete columns wrapped partially with FRP could be calculated as:

$$
\frac{f_{c c}^{\prime}}{f_{c o}^{\prime}}=1+3.3 k_{e} \frac{f_{l}^{\prime}}{f_{c o}^{\prime}}
$$
optimization of the wrapping schemes. The notation of the specimens consists of three parts:

Where $k_{e}$ is estimated based on Eq. 4 and $f_{l}$ shown in the following equation is the equivalent confining pressure from the FRP, assumed to be uniformly distributed along the longitudinal axis of the column.

$$
f_{l}^{\prime}=\frac{2 E_{f} \varepsilon_{f e} t}{D} \frac{w}{w+s}
$$

where $w$ is the width of FRP bands and $s$ is the clear spacing between FRP bands as shown in Fig. 1b.

\section{Experimental Program}

\section{Design of Experiments}

A total of thirty three FRP confined concrete cylinders were cast and tested at the High Bay Laboratory of the University of Wollongong. The dimensions of the concrete cylinder specimens were $150 \mathrm{~mm}$ in diameter and $300 \mathrm{~mm}$ in height. All the specimens were cast from the same batch of concrete. The 28 day cylinder compressive strength was $52 \mathrm{MPa}$.

The experimental program was composed of several groups of cylinders in order to evaluate the confinement efficacy between partially and fully wrapping schemes in terms of the first part states the type of confining FRP material, with " $G$ ” and "C" representing GFRP and CFRP respectively. The second part is either a letter " $R$ ", "F", and "P" stating the name 
111 of the sub-group, namely, reference group (R), fully wrapped group (F) and partially wrapped

112 group (P). The last part of the specimen notation is a number which indicates the number of

113 FRP layers. Details of the specimens are presented in Table 1.

114 The partially wrapped specimens contain FRP bands which are $25 \mathrm{~mm}$ in width spaced evenly

115 along the height of the specimen. The optimized partially wrapped specimens include two

116 numbers in the notation, for example GP31. The first number indicates the number of $25 \mathrm{~mm}$

117 evenly spaced partial FRP layers and the second number depicts the number of FRP layers in

118 between these evenly spaced partial layers. These specimens were designed such that they

119 follow a non-uniform wrapping configuration but ensure the specimen is fully confined at

120 every location. The thicker band is called a tie band and the thinner band is called a cover

121 band. Taking specimen GP31 as an example, the tie bands have three FRP layers which are 25

$122 \mathrm{~mm}$ in width, while the cover bands have one FRP layer as shown in Figure 2. Three identical

123 specimens were made for each wrapping scheme.

124 In order to analyze the confinement effectiveness between different wrapping schemes, the specimens were divided in four groups (as shown in Table 1) such that the specimens in each group incorporate the same amount of FRP but in a different wrapping scheme, either fully,

127 partially or optimized non-uniformly wrapped. The specimens in the first group are reference

128 specimens which did not include any internal or external reinforcement. The specimens in the

129 second and third groups were confined by GFRP and CFRP respectively, such that the fully, 130 partially and optimized non-uniform wrapping schemes were equivalent to two layers of full 131 wrapping. Similarly, the wrapping schemes of the specimens in the fourth group were 132 equivalent to three layers of full wrapping.

133 After 28 days, the specimens were wrapped with a number of FRP layers as shown in Table 1.

134 The adhesive used was a mixture of epoxy resin and hardener at 5:1 ratio. Before the first 
135 layer of FRP was attached, the adhesive was spread onto the surface of the specimen and

136 CFRP was attached onto the surface with the main fibers oriented in the hoop direction. After

137 the first layer, the adhesive was spread onto the surface of the first layer of FRP and the

138 second layer was continuously bonded. The third layer of FRP was applied in a similar

139 manner, ensuring that $100 \mathrm{~mm}$ overlap was maintained. The ends of each wrapped specimen

140 were strengthened with additional one layer of FRP strips $25 \mathrm{~mm}$ in width.

\section{Instrumentation}

142 In order to measure the hoop strains of the FRP jacket, three strain gages with a gage length

143 of $5 \mathrm{~mm}$ were attached at the mid height of the specimens and evenly distributed away from

144 the overlap for the fully wrapped specimens. In the partially wrapped specimens, three strain

145 gages were bonded symmetrically on a tie band and other three were bonded on a cover band

146 at midheight of the specimen.

147 Furthermore, a longitudinal compressometer as shown in Fig. 3 was used to measure the axial

148 strain of the specimens. A Linear variable differential transformer (LVDT) was mounted on 149 the upper ring and the tip of the LVDT rests on an anvil. The readability, the accuracy, and 150 the repeatability of the LVDT complies with the Australian standard (Australian Standard1511545 1976).

152 The compression tests for all the specimens were conducted using the Denison $5000 \mathrm{kN}$ 153 capacity testing machine. The specimens were capped with high strength plaster to ensure full

154 contact between the loading plate and the specimen. Calibration was carried out to ensure that 155 the specimens were placed at the center of the testing machine. Each specimen was first 156 loaded to around $30 \%$ of its unconfined capacity to check the alignment. If required, the 157 specimen was unloaded, realigned, and loaded again. The tests were conducted as deflection 
158

159

160

161

162

163

164

165

166

167

168

169

170

171

172

173

174

175

176

177

178

179

180

controlled with a rate of $0.5 \mathrm{~mm} / \mathrm{min}$. The readings of the load, LVDT and strain gages were taken using a data logging system and were subsequently saved in a control computer.

\section{Experimental Results}

\section{Preliminary tests}

The actual compressive strength of unconfined concrete calculated from three reference specimens (R1, R2, and R3) was $54 \mathrm{MPa}$. The axial strain of unconfined concrete at the maximum load was $0.23 \%$. In this study two types of CFRP were used to confine the concrete, which both had a unidirectional fiber density of $340 \mathrm{~g} / \mathrm{m}^{2}$ and a nominal thickness of $0.45 \mathrm{~mm}$, but with varying nominal widths of $75 \mathrm{~mm}$ and $25 \mathrm{~mm}$. The GFRP utilized had a unidirectional fiber density of $440 \mathrm{~g} / \mathrm{m}^{2}$, a nominal thickness of $0.35 \mathrm{~mm}$ and a nominal width of $50 \mathrm{~mm}$.

Five coupons for each type of FRP were made according to ASTM D7565 (2010) and tested to determine the mechanical properties. The two types of CFRP coupons were made of three layers of FRP with a nominal thickness of $1.35 \mathrm{~mm}$ and both types had very similar properties as shown in Table 2. For simplicity the coupons produced from the $75 \mathrm{~mm}$ tape are denoted by CFRP (75) while the coupons from the $25 \mathrm{~mm}$ tape are referred to as CFRP (25). For GFRP, two-layered coupons containing two overlapping fiber sheets were prepared and tested. The nominal thickness of the coupons was $0.7 \mathrm{~mm}$. All coupons had the dimensions 25 mm x $250 \mathrm{~mm}$. The epoxy resin had $54 \mathrm{MPa}$ tensile strength, 2.8 GPa tensile modulus and 3.4\% tensile elongation (West System n.d. 2015).

\section{Failure Modes}

All specimens were tested until failure. The specimens wrapped fully with FRP (CF2, CF3, and GF2) failed by rupture of FRP at the midheight. The failure surface of the fully wrapped 
181

182

specimens was found to be approximately 45 degree inclined, as shown in Fig. 4a. Meanwhile, the partially wrapped specimens (CP40, CP60, and GP40) showed many small cracks on the concrete surface at a stress equal to the unconfined concrete strength, as shown in Fig. 4b. The concrete between the FRP bands, close to the outer surface of the specimen, started crushing while the concrete core was still confined by the FRP. Cracks on the concrete surface developed as the applied load increased, as shown in Fig. 4c. At the very high stress level, the concrete between the FRP bands spalled off while the concrete under the FRP bands and the core were still confined. These specimens then failed explosively by FRP rupture at the midheight (Fig. 4d).

The angle of the failure surface with respect to the horizon for the partially wrapped specimens was significantly different from the fully wrapping specimens. As shown in Fig. $4 \mathrm{~d}$, the failure surface took place at the spacing between FRP bands. This change of the failure surface depends on the wrapping schemes and the stiffness of the FRP bands. When the axial stress of the confined concrete was higher than the unconfined concrete strength, the 45 degree failure surface may have originally transpired in the concrete cores, but cracks were arrested by FRP bands under the high stress stage. If the stiffness of the FRP bands is not strong enough (Specimen GP40) to prevent the development of the cracks, the failure surface takes place at approximately 45 degrees as shown in Fig. 4e. In contrast, the stiffness of the FRP bands in Specimens CP40 and CP60 is great enough so that it changed the failure surface as depicted in Fig. 4d. It is worth mentioning that the stiffness of the FRP bands affects the tangent modulus of FRP-confined concrete. Tamuzs et al. (2008) suggested that the low value of the tangent modulus causes column stability collapse directly as the unconfined concrete strength level is surpassed. 
204 Furthermore, specimens with optimized non-uniform wrapping schemes showed a different 205 failure mode as compared to the others. At a stress level equal to the unconfined concrete 206 strength, the concrete was still confined by the FRP tie bands and cover bands. During the 207 loading process, the lateral strains of the tie bands and the cover bands were almost identical, 208 with the exception of Specimen CP40_3. The failure modes of these specimens are similar to 209 those of the full wrapping specimens. The Non-uniform wrapped specimens failed by FRP 210 rupture simultaneously at the two bands (tie band and cover band) at the midheight, as shown 211 in Fig. 4f. It is worth mentioning that intermittent confinement resulted from partial 212 confinement (Specimens GP40, CP40, and CP60) makes the concrete to communicate 213 directly with the surroundings, for instance moisture, heat, and evaporation.

\section{Stress-Strain Relation}

215 Stress-strain relations of the tested specimens were divided into two main types based on the 216 shape of the stress-strain curves. These included specimens in the ascending branch type and 217 descending branch type. A FRP confined concrete column exhibits the ascending type curve 218 as a significant improvement of the compressive strength and strain of a FRP confined 219 concrete column could be expected. Otherwise, FRP confined concrete with a stress-strain 220 curve of the descending type illustrates a concrete stress at the ultimate strain below the 221 compressive strength of unconfined concrete. Specimens wrapped with glass fiber are

222 designed to behave as the descending branch type while specimens wrapped with carbon fiber 223 belong to the ascending branch type. Details of all tested specimens are summarized in Table 2243.

225 Stress-strain relations of specimens wrapped by equivalent two GFRP layers were plotted in

226 Fig. 5. The specimens which were wrapped with an equivalent of two layers of FRP had 227 identical stress-strain curves at the early stages of loading and experienced slight differences 
at the latter stage of testing. Specimens GF2 and GP40 had the descending branch type stress-

229 strain curve while the stress-strain curves of Specimens GP31 kept constant after reaching the unconfined concrete strength and then increased again to failure. The axial stress of Specimens GF2 reached the unconfined concrete strength (54 MPa) and then kept constant until the FRP failed by rupture as shown in Fig. 5a. The average compressive confined 233 concrete strength and strain of Specimens GF2 are $57 \mathrm{MPa}$ and $0.97 \%$, respectively. 234 Although Specimens GP40 obtained a lower maximum stress (53 MPa) as compared to that of 235 Specimens GF2, they achieved a larger maximum axial strain (1.18\%) than the former 236 specimens. The axial strain of Specimens GP40 increased by $21.31 \%$ as compared to that of 237 Specimens GF2 (Fig. 5b). Meanwhile, Specimens GF31 achieved both a higher maximum 238 axial stress (60 MPa) and axial strain (1.02 \%), as compared to Specimen GF2, as shown in 239 Fig. 5c.

240 Apart from the specimens above, the specimens which were wrapped with an equivalent of 241 two layers of FRP, had similar stiffness during the whole loading process, as shown in Fig.

242 6. The maximum axial stress of Specimens CF2 was 99 MPa and its corresponding axial 243 strain was 2.13\%. Specimens CP40 reached the maximum axial stress at $95 \mathrm{MPa}$ and the 244 corresponding axial strain at 2.08\%. Specimen CP40_1 failed by premature rupture of FRP ( $\varepsilon_{l}$ $245=1.18 \%$ ) that resulted in very lower maximum axial stress. The average maximum axial 246 stress and axial strain of Specimens CP31 were $98 \mathrm{MPa}$ and $2.12 \%$, respectively.

247 The specimens that were wrapped with an equivalent of three layers of FRP had similar 248 stress-strain curves but experienced a slight difference in the axial stiffness for the whole 249 loading process as shown in Fig. 7. Specimens CF3 obtained average maximum axial stress 250 and strain at $122 \mathrm{MPa}$ and $2.84 \%$, respectively (Fig. 7a). The partially wrapped Specimens 251 CP60 again had a lower compressive strength but higher axial strain as compared to those of 
Specimens CF3. As shown in Fig. 7b, Specimens CP60 failed at the average compressive

253 strength of $116 \mathrm{MPa}$ and axial strain of $3.25 \%$. The axial strain for the specimens CP60 254 increased by $14.33 \%$ in comparison with the Specimens CF3. As compared to Specimens 255 CF3, the non-uniformly wrapped Specimens CP42 had both higher compressive strength and axial strain. Fig. 7d shows that Specimens CP42 failed at the average compressive strength of $257128 \mathrm{MPa}$ and strain of $3.16 \%$. As a result, the compressive strength and axial strain of these 258 specimens respectively increased by $5.29 \%$ and $11.16 \%$ as compared to Specimens CF3. In 259 order to compare the effectiveness of different wrapping schemes, the stress-strain curves of five specimens are plotted in Fig. 7e. In reference to this figure, it can be seen that the partially wrapped Specimens CP60 experienced a lower maximum stress and a higher maximum strain, as compared to Specimens CF3. On the hand, the non-uniformly wrapped specimens CP42 experienced both a higher maximum strain and stress in comparison with Specimens CF3. These findings have also been confirmed by specimens in Group GF2, as shown in Fig. 5d.

\section{Analysis and Discussions}

\section{Lateral Strain}

268 The lateral strain of all the specimens are obtained by taking the average of readings from 269 three strain gages evenly placed along the FRP at locations away from the overlap. For each 270 specimen, the actual rupture strain of FRP is presented in Table 3. In order to investigate the 271 effectiveness of the fiber, the strain efficiency factor $k_{\varepsilon}$ is adopted, which is the ratio of the 272 actual rupture strain of FRP in confined specimens and the rupture strain of the FRP obtained 273 from the tensile coupon testing. As can be seen from Table 3, the strain efficiency factors of 274 fully wrapped specimens are approximately 0.83 and 0.87 for glass fiber and carbon fiber, 275 respectively. For glass fiber, the strain efficiency factor of partially wrapped specimens was 
0.77 and the corresponding number for non-uniformly wrapped specimens was 0.91 .

277 Meanwhile, the strain efficiency factor of specimens partially wrapped with CFRP was 0.80 278 and the corresponding number for non-uniformly wrapped specimens was 0.91. The

279

280

281

282

283

284

285 experimental results have shown that the effectiveness of the fiber reduces in the partial wrapping scheme, but increases in the non-uniformly wrapping scheme.

There is a consensus that the presence of the triaxial stress state in FRP affects the actual rupture strain of the fiber (Chen et al. 2013). In this experimental program, it is obvious that the axial stress of the FRP jackets in the fully wrapped specimens is higher than that of the non-uniformly wrapped specimens. The discontinuity of the jacket in the non-uniformly wrapped specimens reduces the axial stress of the FRP jacket, which could be a reason for the increase in the strain efficiency factor in these specimens. Thus, the non-uniformly wrapped specimens had a higher value of $k_{\varepsilon}$, resulting in a higher confined strength and strain. In other words, the discontinuity of the jackets of the partially wrapped specimens did not increase the strain efficiency factor. The partially wrapped specimens experienced a different failure mode as compared with the other wrapping schemes. This different failure mode in partially wrapped specimens may be the reason behind the slight decrease in the strain efficiency factor for these specimens.

In addition, the lateral strain of the non-uniformly wrapped specimens at both the tie bands and cover bands of the FRP is investigated. For example, the lateral strain - axial stress of Specimen CP40_3 (Fig. 8), illustrates that the lateral strain of FRP in a cover band is slightly higher than that of a tie band at any axial stress state. However, there was no difference in the lateral strain in other specimens.

\section{Analytical Verification}


299

300

301

302

303

304

305

306

307

308

309

310

311

312

313

In order to predict the compressive strength of the tested specimens, the procedure in the section Confinement Mechanism is used. It is noted that the actual lateral strain of each specimen was used in these calculations. The maximum axial strain of the tested specimens is predicted based on the study by Pham and Hadi (2013), in which the relationship between the energies absorbed by the whole column and the FRP was taken into account. Pham and Hadi (2013) assumed that the additional energy in the column core equals the area under the experimental stress-strain curves starting from the value of unconfined concrete strain:

$$
U_{c c}=\int_{\varepsilon_{c o}}^{\varepsilon_{c c}} f_{c} d \varepsilon_{c}=\frac{\left(\varepsilon_{c c}-\varepsilon_{c o}\right)\left(f_{c o}^{\prime}+f_{c c}^{\prime}\right)}{2}
$$

where $U_{c c}$ is the volumetric strain energy of confined concrete, $f_{c}$ is the stress of confined concrete, and $d \varepsilon_{c}$ is an increment of the axial strain.

However, the concrete in the partially wrapped columns is confined in the effective area as shown in Fig. 1. To determine the volumetric strain energy of confined concrete for the whole columns, the value of the confined concrete strength needs to be modified by the confinement effective coefficient $\left(k_{e}\right)$, which leads to the following equation:

$$
U_{c c}=\int_{\varepsilon_{c o}}^{\varepsilon_{c c}} f_{c} d \varepsilon_{c}=\frac{\left(\varepsilon_{c c}-\varepsilon_{c o}\right)\left(f_{c o}^{\prime}+k_{e} f_{c c}^{\prime}\right)}{2}
$$

314 Similarly, the energy absorbed by FRP could be calculated as follows:

$$
W_{f}=\rho_{f} A_{c}\left(\frac{1}{2} f_{f e} \varepsilon_{f e}\right)
$$

316 where $W_{f}$ is the strain energy of FRP, and $\rho_{f}$ is the volumetric ratio of FRP as shown in Eq. 10. 


$$
\rho_{f}=\frac{4 t}{D}
$$

319 The compressive strain of columns partially wrapped with FRP is calculated as follows:

$$
\varepsilon_{c c}=\varepsilon_{c o}+\frac{2 k t f_{f e} \varepsilon_{f e}}{D\left(f_{c o}^{\prime}+k_{e} f_{c c}^{\prime}\right)}
$$

321 The predicted results of the compressive strength and strain of the tested specimens are

322 presented in Table 4. This table has shown that the predicted results are quite close to the 323 experimental results.

\section{Conclusions}

325 This study presented an experimental study on the optimization of concrete cylinders wrapped 326 with FRP. The same amount of FRP was used in each group of specimens but with different 327 wrapping schemes, in order to investigate the confinement efficacy between fully, partially 328 and a proposed non-uniform wrapping scheme for FRP-confined concrete. The findings 329 presented in this study are summarized as follows:

330 1. For specimens belonging to the descending branch type, the partially wrapped specimens had a lower compressive strength but a higher strain as compared to the corresponding fully wrapped specimens. On the other hand, the non-uniform wrapped specimens experienced both a higher compressive strength and axial strain in comparison

334 with the fully wrapped specimens.

2. For heavily FRP-confined specimens (CF3, CP60, CP51 and CP42), partial and nonuniform wrapped specimens provided a higher axial strain as compared to that of fully wrapped specimens. 
3. The partial wrapping scheme changes the failure modes of the specimens. If the FRP jackets are strong enough, the angle of the failure surface significantly reduces.

4. The actual rupture strain of the FRP jackets is different for each wrapping scheme. The strain efficiency factor in the full wrapping scheme is greater than that of the partial wrapping scheme but is less than that of the non-uniform wrapping scheme.

5. An equation is proposed to estimate the axial strain of partially FRP-confined concrete circular columns.

Finally, this study proposed a new wrapping scheme that uses the same amount of FRP as compared to the conventional fully wrapping scheme, in order to yield a higher compressive strength and strain. However, further studies are required to theoretically investigate the behavior of non-uniform wrapped specimens.

\section{Acknowledgement}

350 The authors would like to acknowledge the technical assistance of Messrs. Alan Grant, 351 Cameron Neilson, Fernando Escribano, Ritchie McLean and Colin Devenish. The 352 contribution of Mr. Elliot Davison is greatly appreciated. Furthermore, the first author would 353 like to thank the Vietnamese Government and the University of Wollongong for the support 354 of his full Ph.D. scholarship.

\section{Notations}

$A_{c} \quad=$ cross-sectional area;

$357 A_{e} \quad=$ area of effectively confined concrete core;

$358 \quad D \quad=$ diameter of the column section;

$359 d \varepsilon_{c}=$ increment of the axial strain;

$360 E_{f} \quad=$ elastic modulus of FRP; 


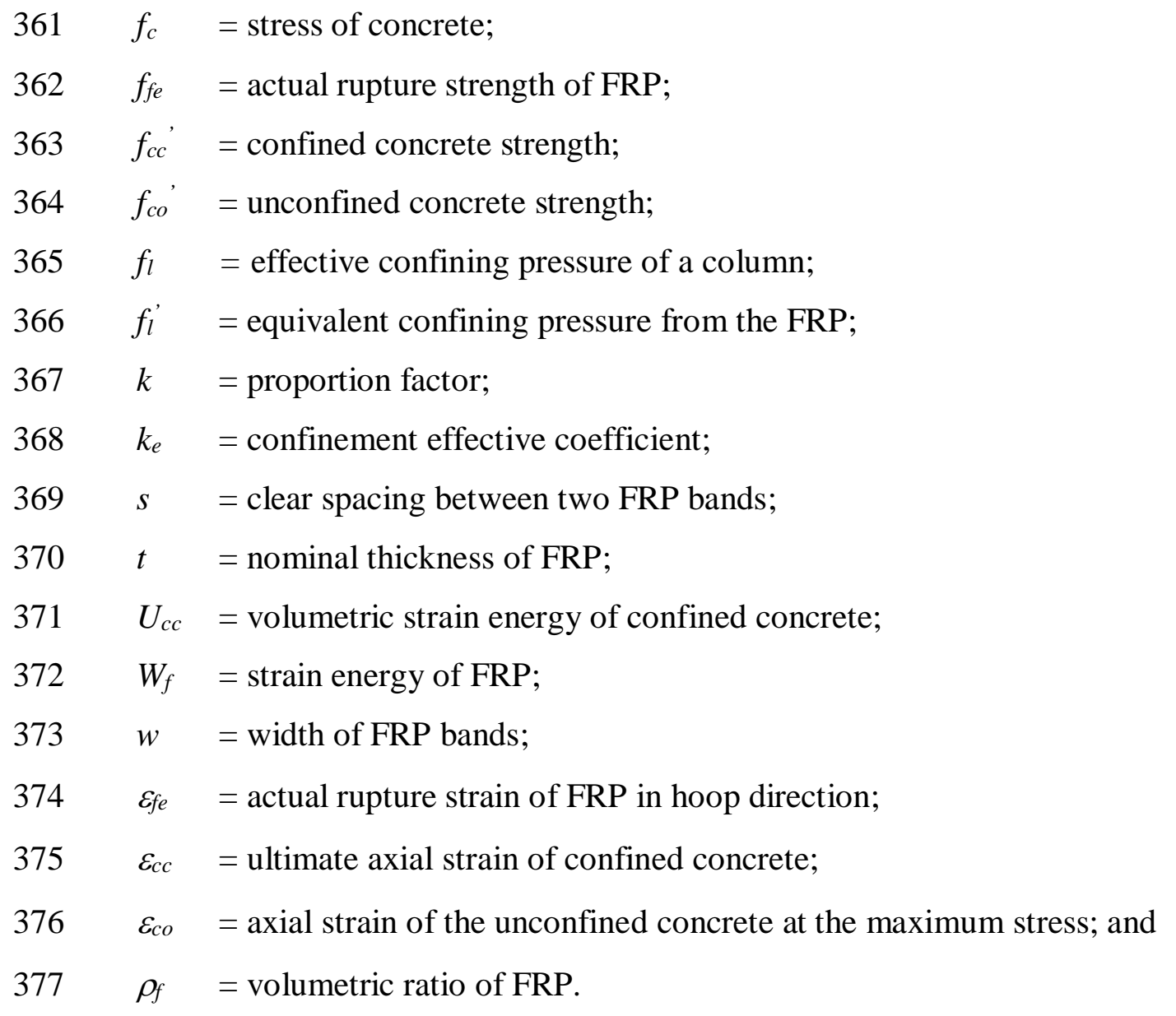

\section{$378 \quad$ References}

ACI 440.2R-08 (2008). "Guide for the Design and Construction of Externally Bonded FRP Systems for Strengthening Concrete Structures." 440.2R-08, American Concrete Institute, Farmington Hills, MI.

ASTM (2010). "Standard test method for tensile properties of fiber reinforced polymer matrix composites used for strengthening of civil structures." D7565:2010West Conshohocken, PA.

Australian Standard-1545 (1976). "Methods for the Calibration and Grading of Extenometers." 1545-1976Homebush, NSW 2140.

Chaallal, O., Shahawy, M., and Hassan, M. (2003). "Performance of axially loaded short rectangular columns strengthened with carbon fiber-reinforced polymer wrapping." $J$ Compos Constr, 7(3), 200-208.

Chen, J., Li, S., and Bisby, L. (2013). "Factors Affecting the Ultimate Condition of FRPWrapped Concrete Columns." J Compos Constr, 17(1), 67-78.

Colomb, F., Tobbi, H., Ferrier, E., and Hamelin, P. (2008). "Seismic retrofit of reinforced concrete short columns by CFRP materials." Compos Struct, 82(4), 475-487.

De Luca, A., and Nanni, A. (2011). "Single-Parameter Methodology for the Prediction of the Stress-Strain Behavior of FRP-Confined RC Square Columns." J Compos Constr, 15(3), 384-392. 
fib (2001). "Externally bonded FRP reinforcement for RC structures." Bulletin, 14, 138.

Hadi, M. N. S., Pham, T. M., and Lei, X. (2013). "New Method of Strengthening Reinforced Concrete Square Columns by Circularizing and Wrapping with Fiber-Reinforced Polymer or Steel Straps." J Compos Constr, 17(2), 229-238.

Lam, L., and Teng, J. G. (2003). "Design-oriented stress-strain model for FRP-confined concrete." Constr Build Mater, 17(6-7), 471-489.

Maaddawy, T. E. (2009). "Strengthening of Eccentrically Loaded Reinforced Concrete Columns with Fiber-Reinforced Polymer Wrapping System: Experimental Investigation and Analytical Modeling." J Compos Constr, 13(1), 13-24.

Mander, J. B., Park, R., and Priestley, M. J. N. (1988). "Theoretical Stress-Strain Model for Confined Concrete." J Struct Eng, 114(8), 1804-1826.

Pham, T. M., Doan, L. V., and Hadi, M. N. S. (2013). "Strengthening square reinforced concrete columns by circularisation and FRP confinement." Constr Build Mater, 49(0), 490-499.

Pham, T. M., and Hadi, M. N. S. (2013). "Strain Estimation of CFRP Confined Concrete Columns Using Energy Approach." J Compos Constr, 17(6), 04013001.

Pham, T. M., and Hadi, M. N. S. (2014a). "Confinement Model for FRP Confined Normaland High-Strength Concrete Circular Columns." Constr Build Mater, 69, 83-90.

Pham, T. M., and Hadi, M. N. S. (2014b). "Predicting Stress and Strain of FRP Confined Rectangular/Square Columns Using Artificial Neural Networks." J Compos Constr, 18(6), 04014019.

Pham, T. M., and Hadi, M. N. S. (2014c). "Stress Prediction Model for FRP Confined Rectangular Concrete Columns with Rounded Corners." J Compos Constr, 18(1), 04013019.

Sheikh, S. A., and Uzumeri, S. M. (1980). "Strength and ductility of tied concrete columns." Journal of the structural division, 106(5), 1079-1102.

Smith, S. T., Kim, S. J., and Zhang, H. W. (2010). "Behavior and Effectiveness of FRP Wrap in the Confinement of Large Concrete Cylinders." J Compos Constr, 14(5), 573-582.

Tamužs, V., Tepfers, R., Zīe, E., and Valdmanis, V. "Mechanical behaviour of FRP-confined concrete columns under axial compressive loading." Proc., 5th International engineering and construction conference (IECC'5). American Society of Civil Engineers, International Committee, Los Angeles Section, 223-241.

Teng, J. G., Jiang, T., Lam, L., and Luo, Y. Z. (2009). "Refinement of a Design-Oriented Stress-Strain Model for FRP-Confined Concrete." J Compos Constr, 13(4), 269-278.

Toutanji, H. A. (1999). "Stress-strain characteristics of concrete columns externally confined with advanced fiber composite sheets." ACI Mater J, 96(3), 397-404.

TR 55 (2012). Design guidance for strengthening concrete structures using fibre composite materials, Concrete Society, Camberley.

Turgay, T., Polat, Z., Koksal, H. O., Doran, B., and Karakoç, C. (2010). "Compressive behavior of large-scale square reinforced concrete columns confined with carbon fiber reinforced polymer jackets." Materials \& Design, 31(1), 357-364. 
438 West System n.d. (2015). "Epoxy resins and hardeners - Physical properties." $439 \quad<$ http://www.westsystem.com/ss/typical-physical-properties>. (Jan. 31, 2015).

440 Wu, Y. F., and Zhou, Y. W. (2010). "Unified Strength Model Based on Hoek-Brown Failure $441 \quad$ Criterion for Circular and Square Concrete Columns Confined by FRP." J Compos $442 \quad$ Constr, 14(2), 175-184. 


\section{$443 \quad$ List of Figures}

444 Figure 1. Confinement mechanism

445 Figure 2. Different wrapping schemes

446 Figure 3. Compressometer

447 Figure 4. Failure modes of the tested specimens

448 Figure 5. Stress-strain relation of Group GF2

449 Figure 6. Stress-strain relation of Group CF2

450 Figure 7. Stress-strain relation of Group CF3

451 Figure 8. Lateral strain - axial stress relationship of Specimen CP40_3 
452 List of Table

453 Table 1. Test matrix

454 Table 2. Results of tensile tests on FRP flat coupon tests

455 Table 3. Experimental results of tested specimens

456 Table 4. Verification of the experimental results 
Table 1. Test matrix

\begin{tabular}{ccccccc}
\hline Group & $\begin{array}{c}\text { No. of } \\
\text { specimens }\end{array}$ & $\begin{array}{c}\text { Type of } \\
\text { FRP }\end{array}$ & $\begin{array}{c}\text { Equivalent FRP } \\
\text { layers with full } \\
\text { wrapping }\end{array}$ & $\begin{array}{c}\text { Width of } \\
\text { each FRP } \\
\text { band } \\
(w, \mathrm{~mm})\end{array}$ & $\begin{array}{c}\text { Clear spacing } \\
(\mathrm{s}, \mathrm{mm})\end{array}$ & $\begin{array}{c}\text { Type of } \\
\text { Wrapping }\end{array}$ \\
\hline R & 3 & - & - & - & - & \\
\hline GF2 & 3 & & & 50 & 0 & Full \\
GP40 & 3 & GFRP & 2 & 25 & 25 & Partial \\
GP31 & 3 & & & 25 & 0 & Non-uniform \\
\hline CF2 & 3 & & & 75 & 0 & Full \\
CP40 & 3 & CFRP & 2 & 25 & 25 & Partial \\
CP31 & 3 & & & 25 & 0 & Non-uniform \\
\hline CF3 & 3 & & & 75 & 0 & Full \\
CP60 & 3 & & & 25 & 25 & Partial \\
CP51 & 3 & CFRP & 3 & 25 & 0 & Non-uniform \\
CP42 & 3 & & & 25 & 0 & Non-uniform \\
\hline
\end{tabular}

458 
Table 2. Results of tensile tests on FRP flat coupons

\begin{tabular}{ccccccc}
\hline $\begin{array}{c}\text { Type of } \\
\text { coupon } \\
\text { specimen }\end{array}$ & $\begin{array}{c}\text { Number } \\
\text { of FRP } \\
\text { layers }\end{array}$ & $\begin{array}{c}\text { Width } \\
(\mathrm{mm})\end{array}$ & $\begin{array}{c}\text { Nominal } \\
\text { thickness } \\
(\mathrm{mm})\end{array}$ & $\begin{array}{c}\text { Average } \\
\text { Elastic } \\
\text { Modulus } \\
(\mathrm{MN} / \mathrm{mm})\end{array}$ & $\begin{array}{c}\text { Average } \\
\text { Tensile } \\
\text { Strength } \\
(\mathrm{kN} / \mathrm{mm})\end{array}$ & $\begin{array}{c}\text { Average } \\
\text { Ultimate } \\
\text { Strain } \\
(\mathrm{mm} / \mathrm{mm})\end{array}$ \\
\hline CFRP (75) & 3 & 25 & 1.35 & 133 & 2171 & 0.0163 \\
CFRP (25) & 3 & 25 & 1.35 & 133 & 2157 & 0.0162 \\
GFRP & 2 & 25 & 0.70 & 29.5 & 582 & 0.0197 \\
\hline
\end{tabular}

$460{ }^{*}$ CFRP (75) denotes the coupons made of the FRP sheets that have $75 \mathrm{~mm}$ width

$461{ }^{* *}$ CFRP (25) denotes the coupons made of the FRP sheets that have 25 mm width 
Table 3. Experimental results of tested specimens

\begin{tabular}{|c|c|c|c|c|c|c|c|c|c|}
\hline \multirow[t]{2}{*}{ Specimen } & \multicolumn{3}{|c|}{ Maximum axial stress } & \multicolumn{3}{|c|}{ Maximum axial strain } & \multicolumn{2}{|l|}{$\begin{array}{l}\text { Maximum } \\
\text { lateral strain }\end{array}$} & \multirow{2}{*}{$\begin{array}{c}\text { Strain } \\
\text { efficiency } \\
\text { factor } \\
k_{\varepsilon}\end{array}$} \\
\hline & $\begin{array}{c}f_{c c}^{\prime} \\
(\mathrm{MPa})\end{array}$ & $\begin{array}{c}\text { Average } \\
(\mathrm{MPa})\end{array}$ & $\begin{array}{c}\text { Increase }^{\#} \\
(\%)\end{array}$ & $\varepsilon_{c c}(\%)$ & $\begin{array}{c}\text { Average } \\
\text { (\%) }\end{array}$ & $\begin{array}{l}\text { Increase }^{\#} \\
(\%)\end{array}$ & $\varepsilon_{l}(\%)$ & $\begin{array}{c}\text { Average } \\
\text { (\%) }\end{array}$ & \\
\hline GF2_1 & 57 & & & 1.30 & & & 1.70 & & \\
\hline GF2_2 & 56 & 57 & - & 0.63 & 0.97 & - & 1.31 & 1.64 & 0.83 \\
\hline GF2_3 & 57 & & & 0.98 & & & 1.91 & & \\
\hline GP40_1 & 55 & & & 1.25 & & & 1.59 & & \\
\hline GP40_2 & 53 & 53 & -6.04 & 1.26 & 1.18 & 21.31 & 1.61 & 1.51 & 0.77 \\
\hline GP40_3 & 51 & & & 1.02 & & & 1.34 & & \\
\hline GP31_1 & 62 & & & 1.31 & & & 1.87 & & \\
\hline GP31_2 & 61 & 60 & 6.56 & 0.66 & 1.02 & 5.49 & 1.79 & 1.80 & 0.91 \\
\hline GP31_3 & 59 & & & 1.10 & & & 1.74 & & \\
\hline CF2_1 & 97 & & & 1.87 & & & 1.35 & & \\
\hline CF2_2 & 99 & 99 & - & 2.23 & 2.13 & - & 1.41 & 1.41 & 0.87 \\
\hline CF2_3 & 101 & & & 2.28 & & & 1.47 & & \\
\hline CP40_1 & 86 & & & 1.58 & & & $1.18^{*}$ & & \\
\hline CP40_2 & 95 & 95 & -3.62 & 2.05 & 2.08 & -2.02 & - & 1.30 & 0.80 \\
\hline CP40_3 & 96 & & & 2.12 & & & 1.42 & & \\
\hline CP31_1 & 97 & & & 2.23 & & & 1.52 & & \\
\hline CP31_2 & 97 & 98 & -1.56 & 1.97 & 2.12 & -0.32 & 1.52 & 1.52 & 0.94 \\
\hline CP31_3 & 99 & & & 2.16 & & & 1.50 & & \\
\hline CF3_1 & 126 & & & 2.88 & & & 1.35 & & \\
\hline CF3_2 & 118 & 122 & - & 2.58 & 2.84 & - & 1.37 & 1.39 & 0.86 \\
\hline CF3_3 & 122 & & & 3.06 & & & 1.45 & & \\
\hline CP60_1 & 113 & & & 3.20 & & & 1.21 & & \\
\hline CP60_2 & 118 & 116 & -4.72 & 3.25 & 3.25 & 14.33 & 1.29 & 1.30 & 0.80 \\
\hline CP60_3 & 117 & & & 3.29 & & & 1.39 & & \\
\hline CP51_1 & 117 & & & 2.96 & & & 1.34 & & \\
\hline CP51_2 & 121 & 119 & -2.04 & 3.21 & 3.09 & 8.58 & 1.52 & 1.43 & 0.88 \\
\hline CP51_3 & 108 & & & 2.17 & & & $1.16^{*}$ & & \\
\hline CP42_1 & 124 & & & 3.12 & & & 1.53 & & \\
\hline CP42_2 & 128 & 128 & 5.29 & 3.33 & 3.16 & 11.16 & 1.46 & 1.50 & 0.92 \\
\hline CP42_3 & 132 & & & 3.03 & & & 1.50 & & \\
\hline
\end{tabular}

$463{ }^{*}$ Specimens performed premature damage

$464{ }^{\#}$ Increase of a specimen compared to the fully wrapping specimens in the same group. 
Table 4. Verification of the experimental results

\begin{tabular}{|c|c|c|c|c|c|c|c|c|c|c|c|c|c|}
\hline \multirow{3}{*}{ Specimen } & \multirow{3}{*}{$\begin{array}{c}D \\
(\mathrm{~mm}) \\
\end{array}$} & \multirow{3}{*}{$\begin{array}{c}t \\
(\mathrm{~mm}) \\
\end{array}$} & \multirow{3}{*}{$\begin{array}{c}S \\
(\mathrm{~mm}) \\
\end{array}$} & \multirow{3}{*}{$\begin{array}{c}w \\
(\mathrm{~mm}) \\
\end{array}$} & \multirow{3}{*}{$k_{\varepsilon}$} & \multirow{3}{*}{$\begin{array}{c}f_{l} \\
(\mathrm{MPa})\end{array}$} & \multirow{3}{*}{$k_{e}{ }^{(*)}$} & \multicolumn{4}{|c|}{ Theoretical Experimental } & \multirow{3}{*}{$\begin{array}{l}\Delta f_{c c} \\
(\%)\end{array}$} & \multirow{3}{*}{$\begin{array}{l}\Delta \varepsilon_{C C} \\
(\%)\end{array}$} \\
\hline & & & & & & & & $f_{c c}{ }^{(* *)}$ & $\varepsilon_{C C}$ & $f_{c c}$ & $\varepsilon_{c c}$ & & \\
\hline & & & & & & & & $(\mathrm{MPa})$ & $(\%)$ & $(\mathrm{MPa})$ & $(\%)$ & & \\
\hline CF2 & 150 & 0.9 & 0 & 0 & 0.87 & 17 & 1.00 & 109 & 2.43 & 99 & 2.13 & 10 & 14 \\
\hline CP40 & 150 & 1.8 & 25 & 25 & 0.80 & 15 & 0.84 & 97 & 2.49 & 95 & 2.08 & 2 & 20 \\
\hline CF3 & 150 & 1.35 & 0 & 0 & 0.86 & 25 & 1.00 & 135 & 2.98 & 122 & 2.84 & 11 & 5 \\
\hline CP60 & 150 & 2.7 & 25 & 25 & 0.80 & 23 & 0.84 & 118 & 3.20 & 116 & 3.25 & 2 & -2 \\
\hline
\end{tabular}

$466 \Delta f_{c c}$ and $\Delta \varepsilon_{c c}=$ difference between the theoretical values and the corresponding experimental

$467 \quad$ values

$468 \quad(*)$ the values of $k_{e}$ were calculated based on Equation 4

$469 \quad(* *)$ the values of $f_{c c}$ were calculated based on Equation 5 


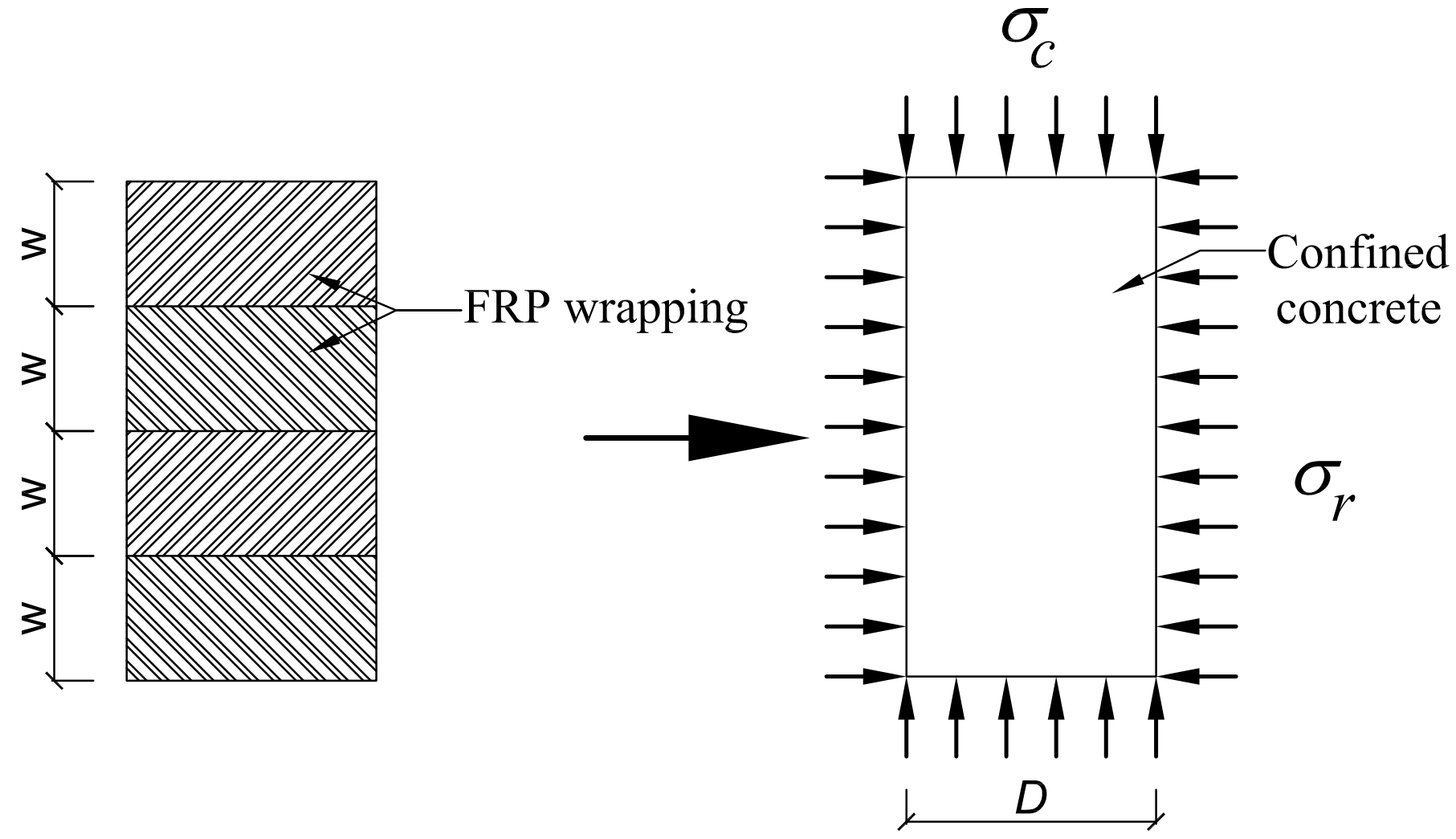

a) Concrete columns wrapped fully with FRP

$\sigma_{c}$

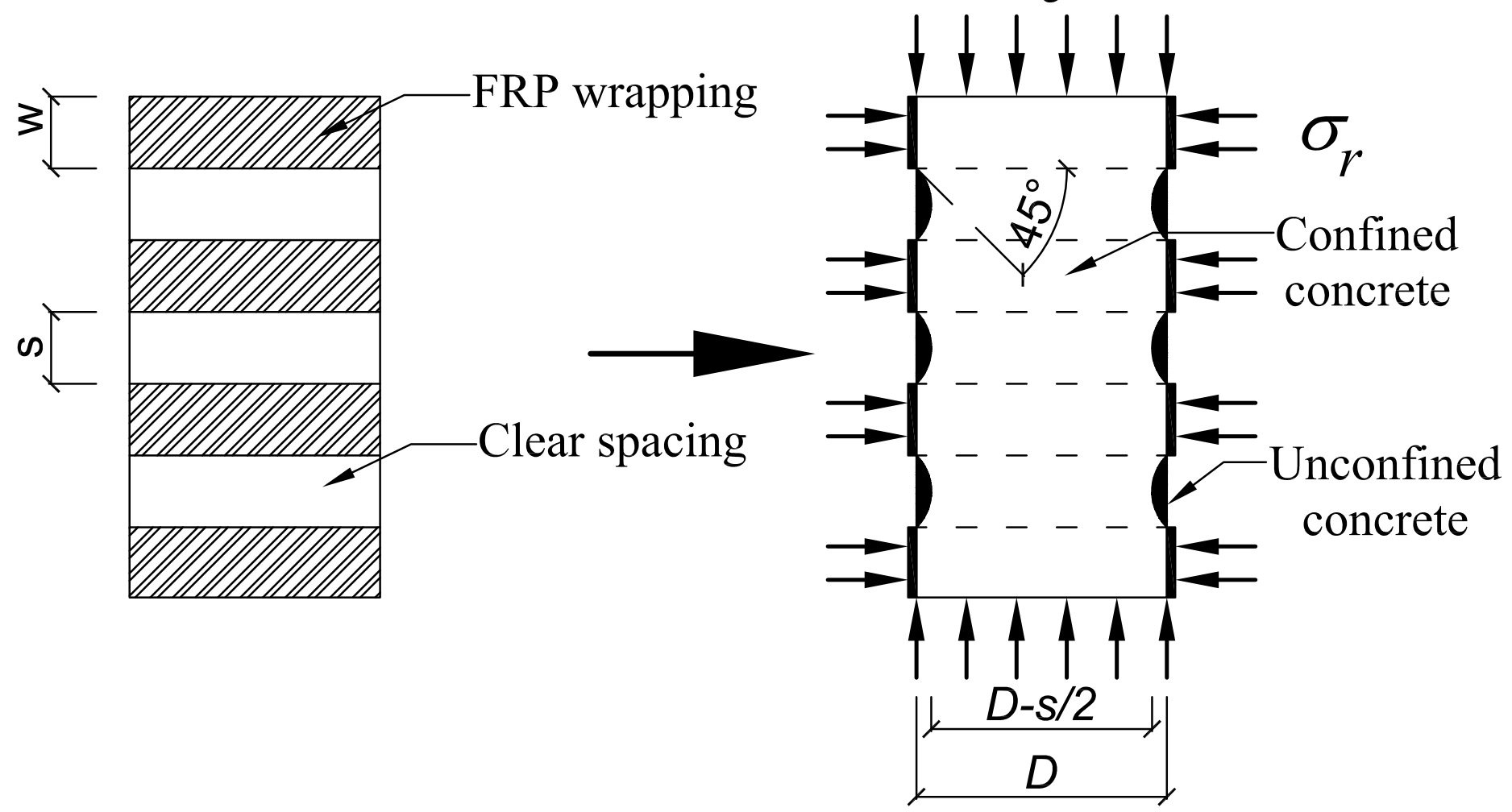

b) Concrete columns wrapped partially with FRP 


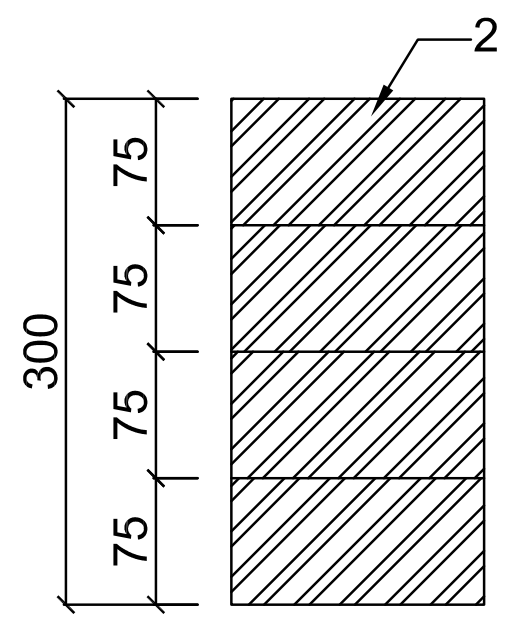

CF2

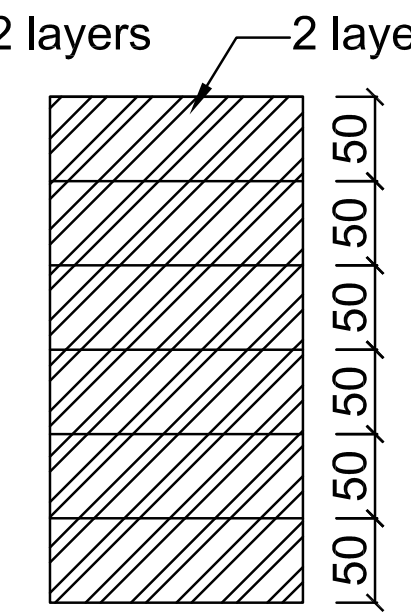

GF2

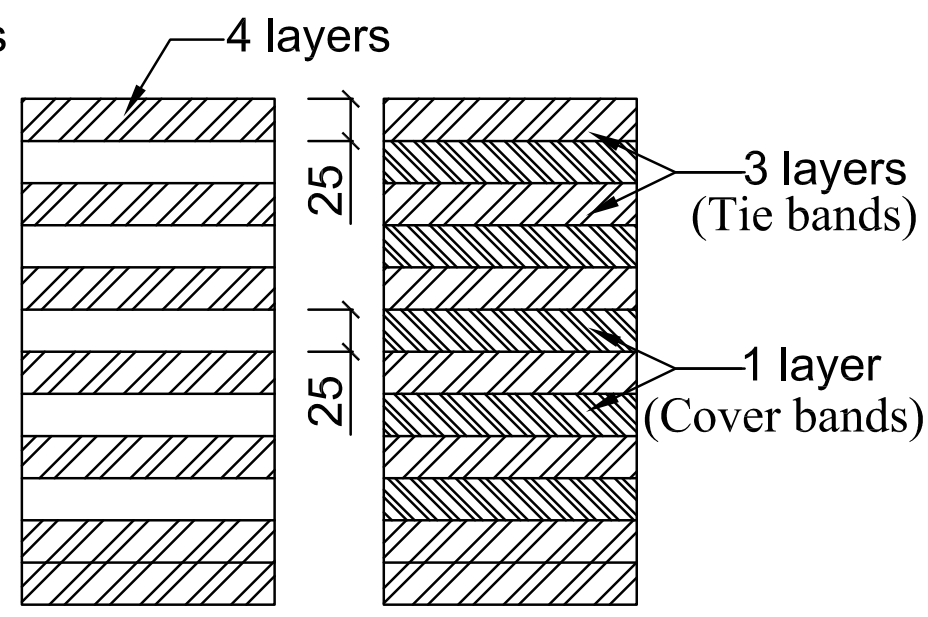

CP40/GP40 CP31/GP31

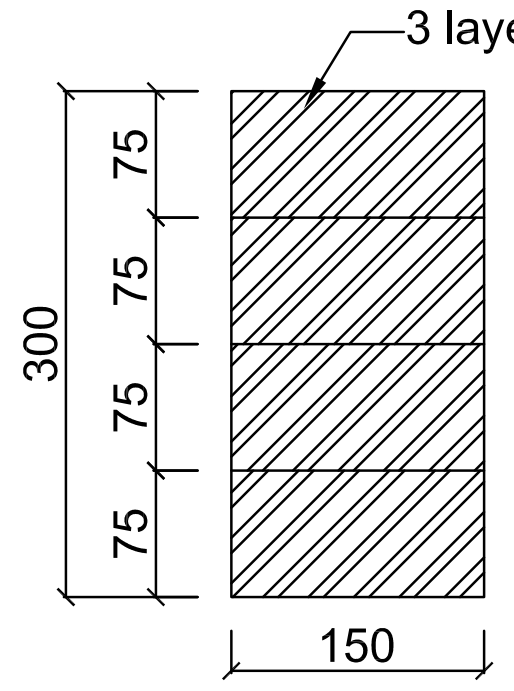

CF3

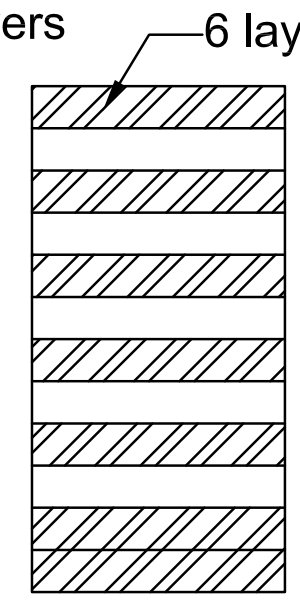

CP60

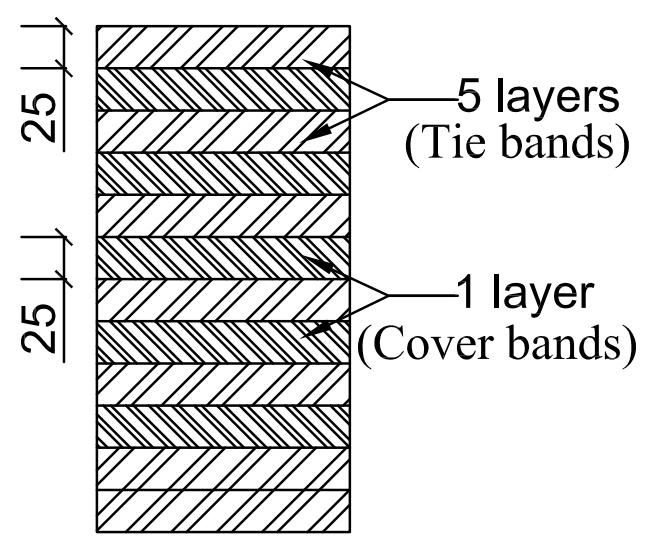

CP51

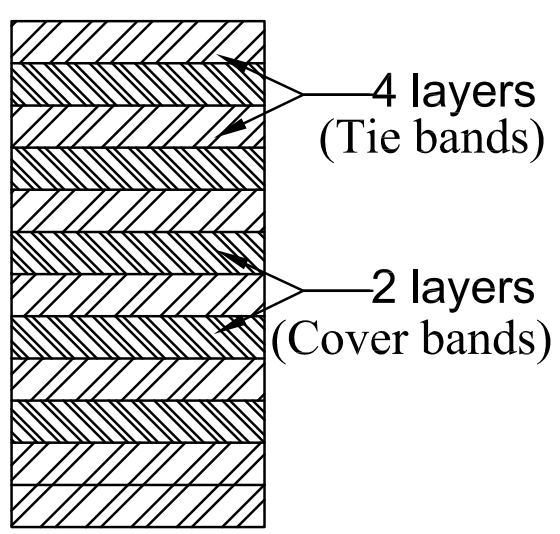

CP42 


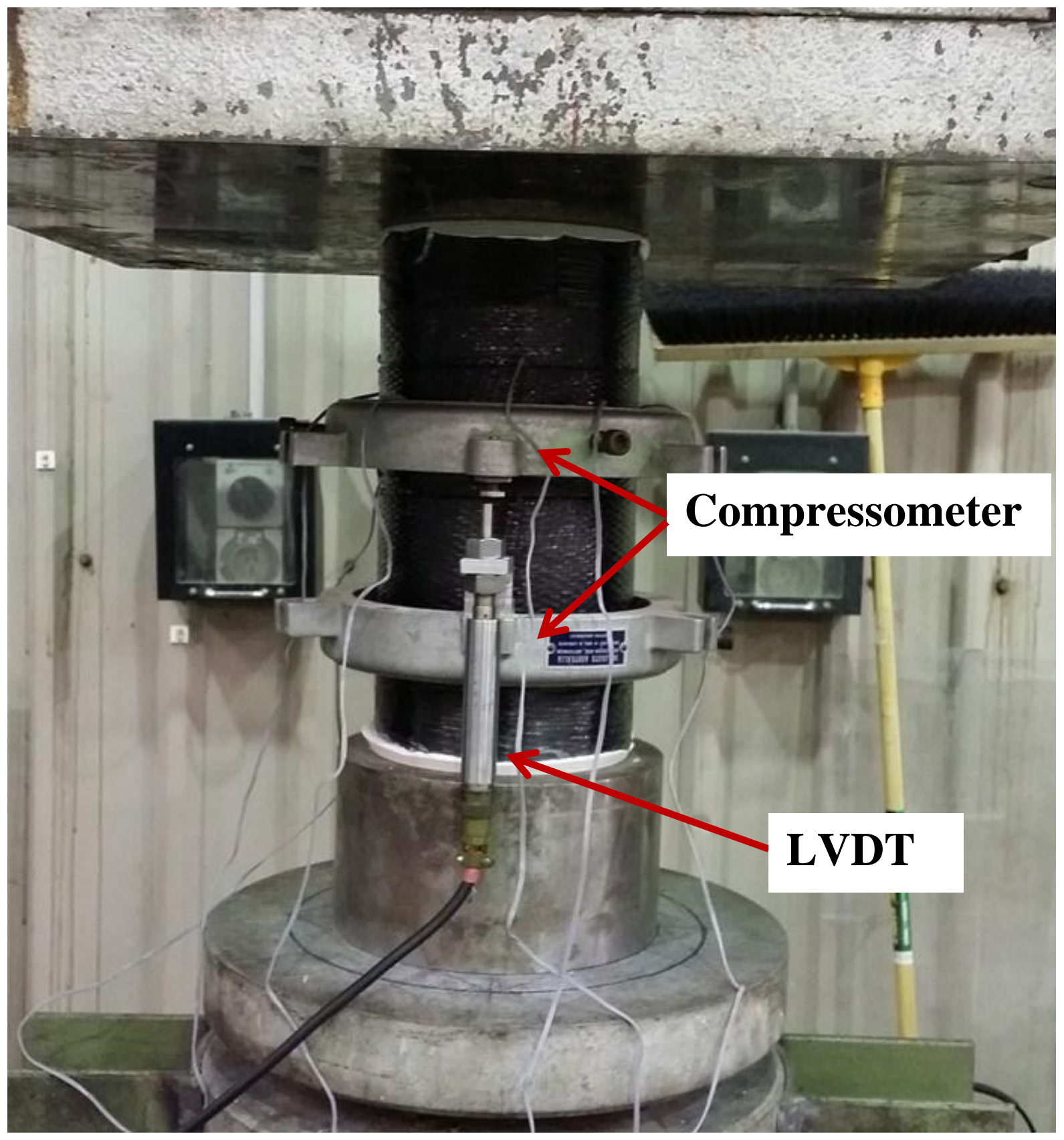




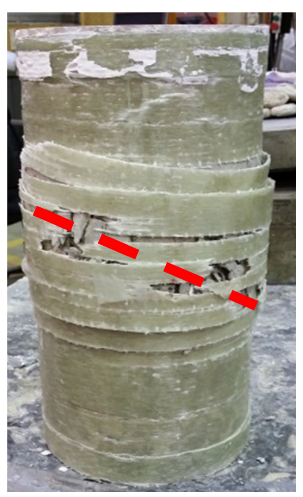

4a. GF2

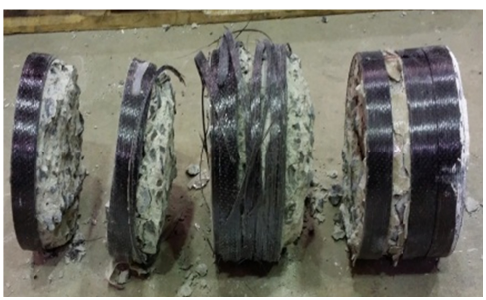

4d. CP60

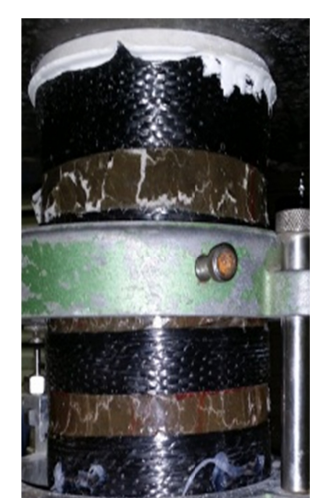

4b. CP40 $\left(\sigma_{c}=f_{c o}{ }^{\prime}\right)$

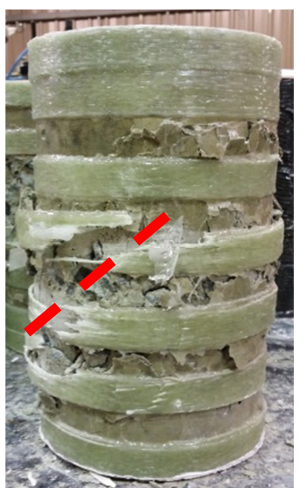

4e. GP40

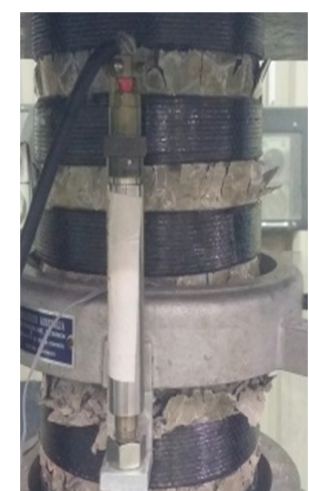

4c. CP40 $\left(\sigma_{c} \sim f_{c u}{ }^{\prime}\right)$

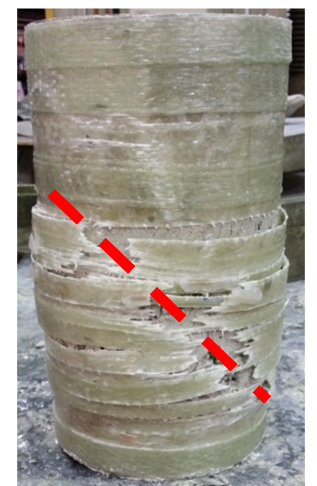

4f. GP31 


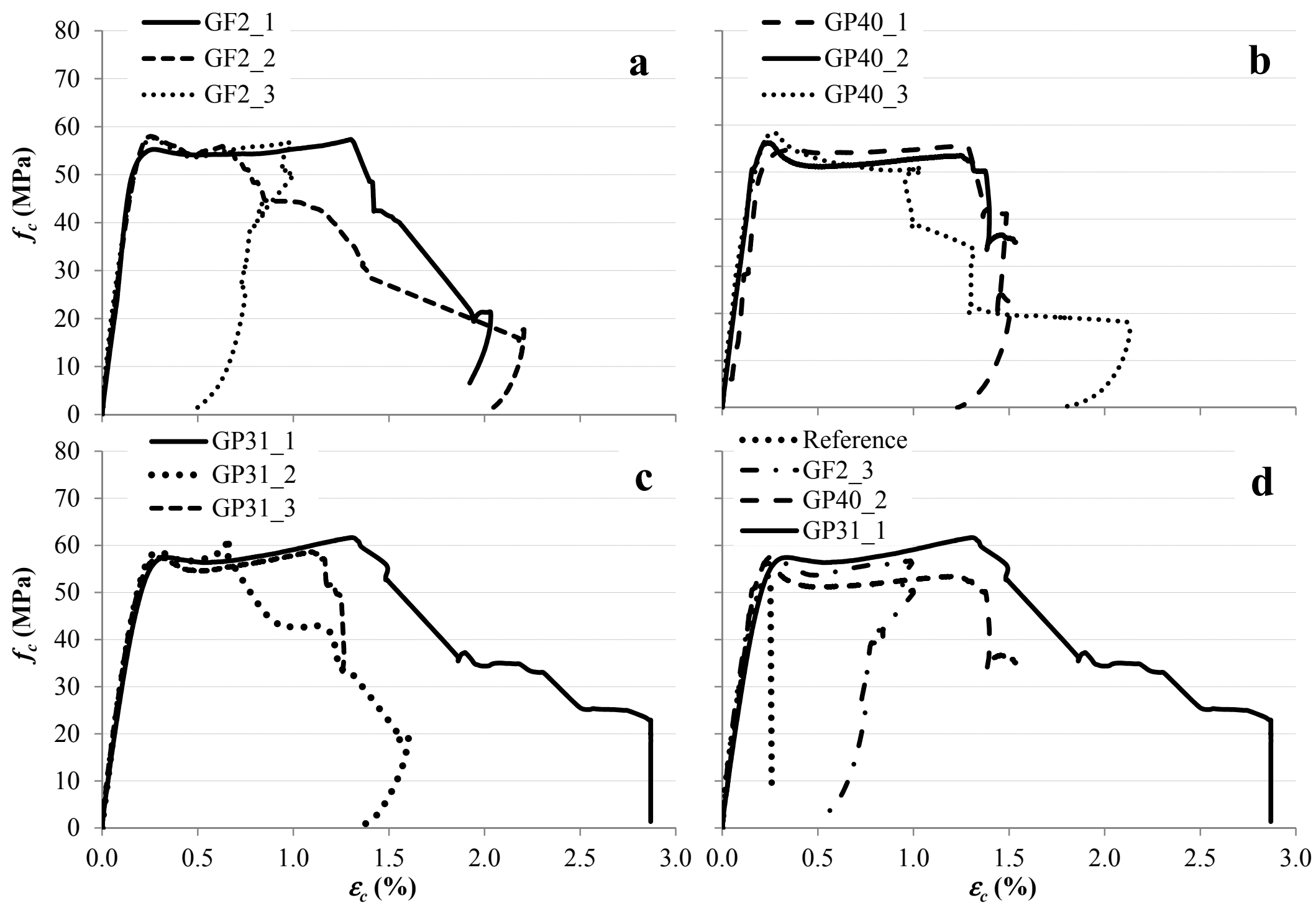




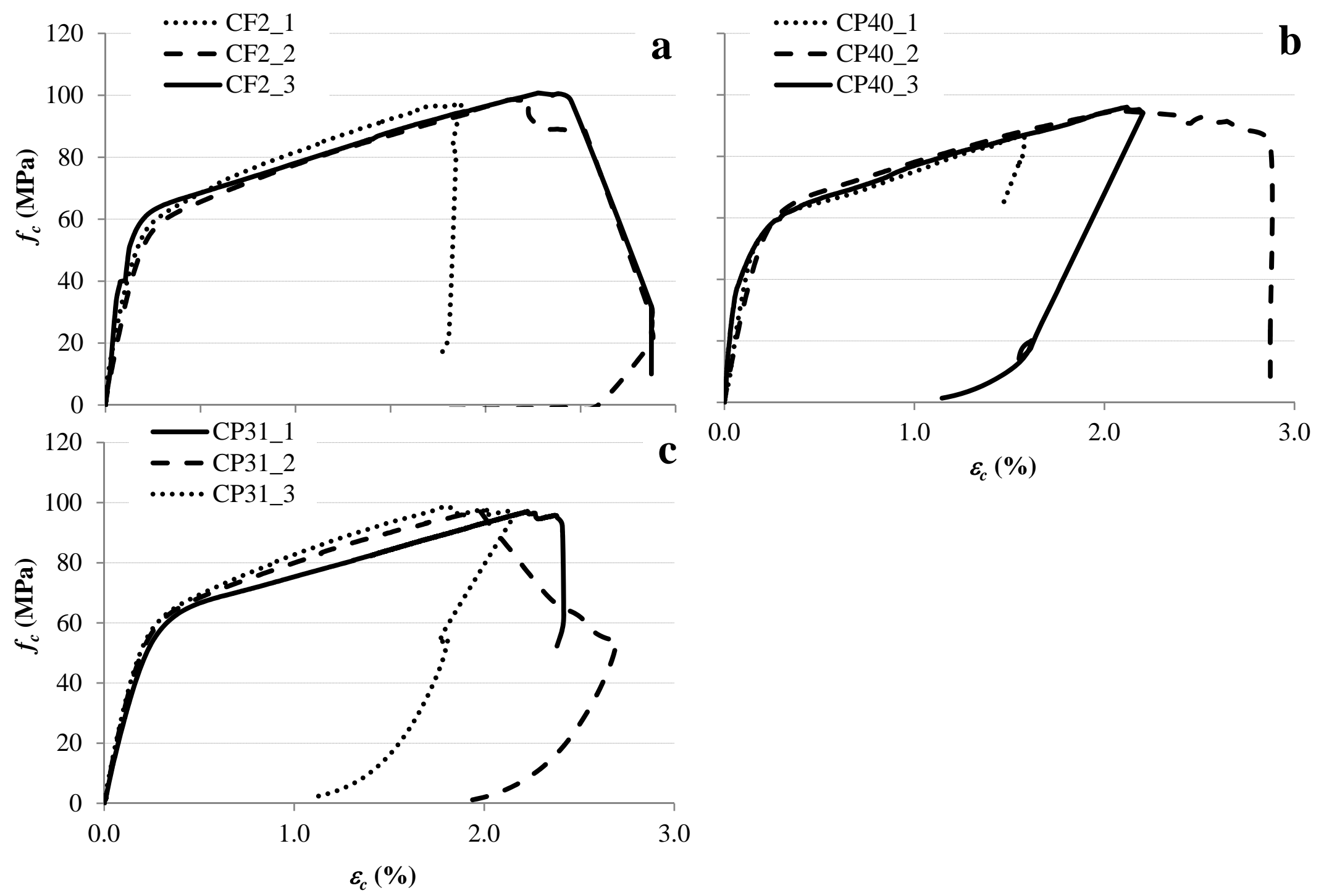




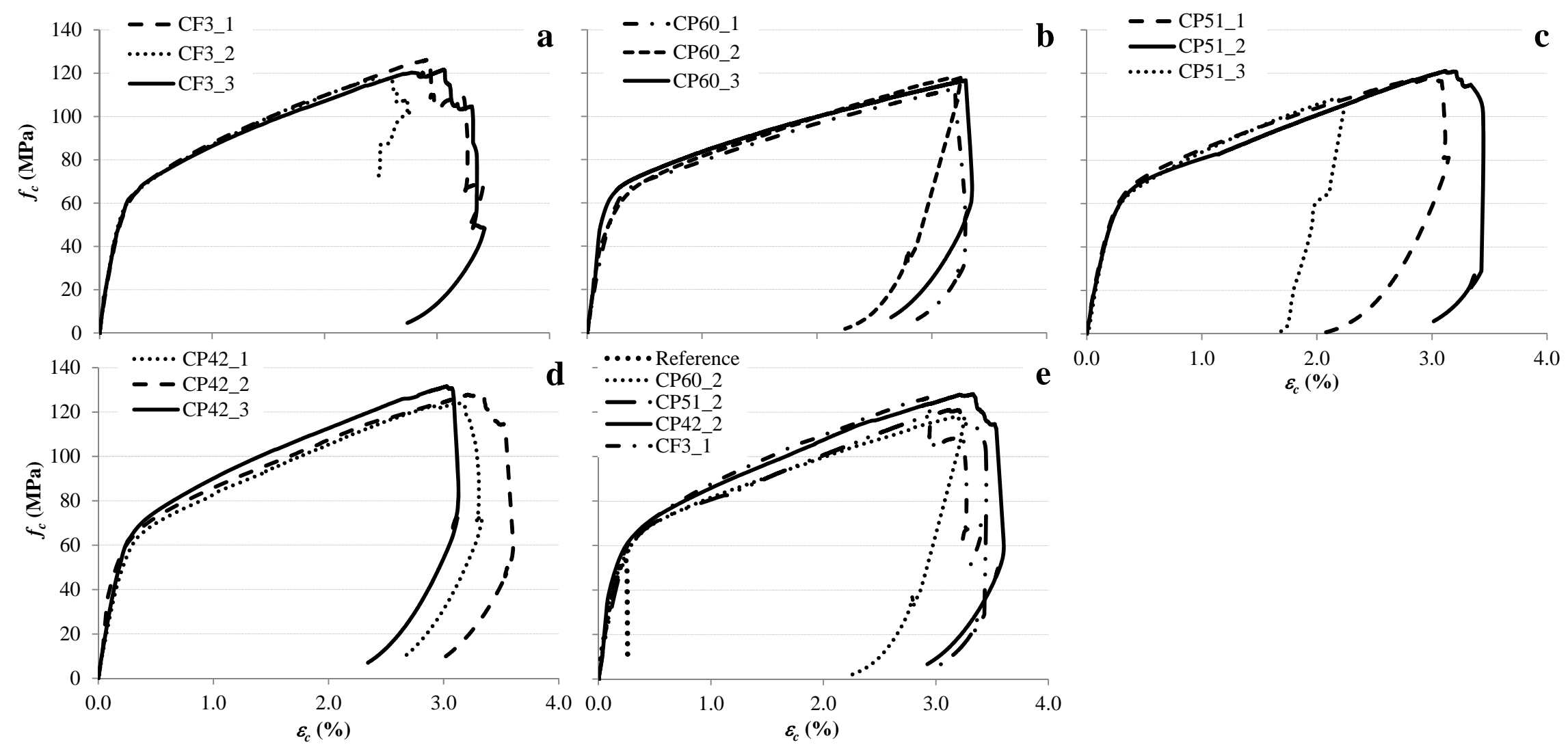


Fig. 8

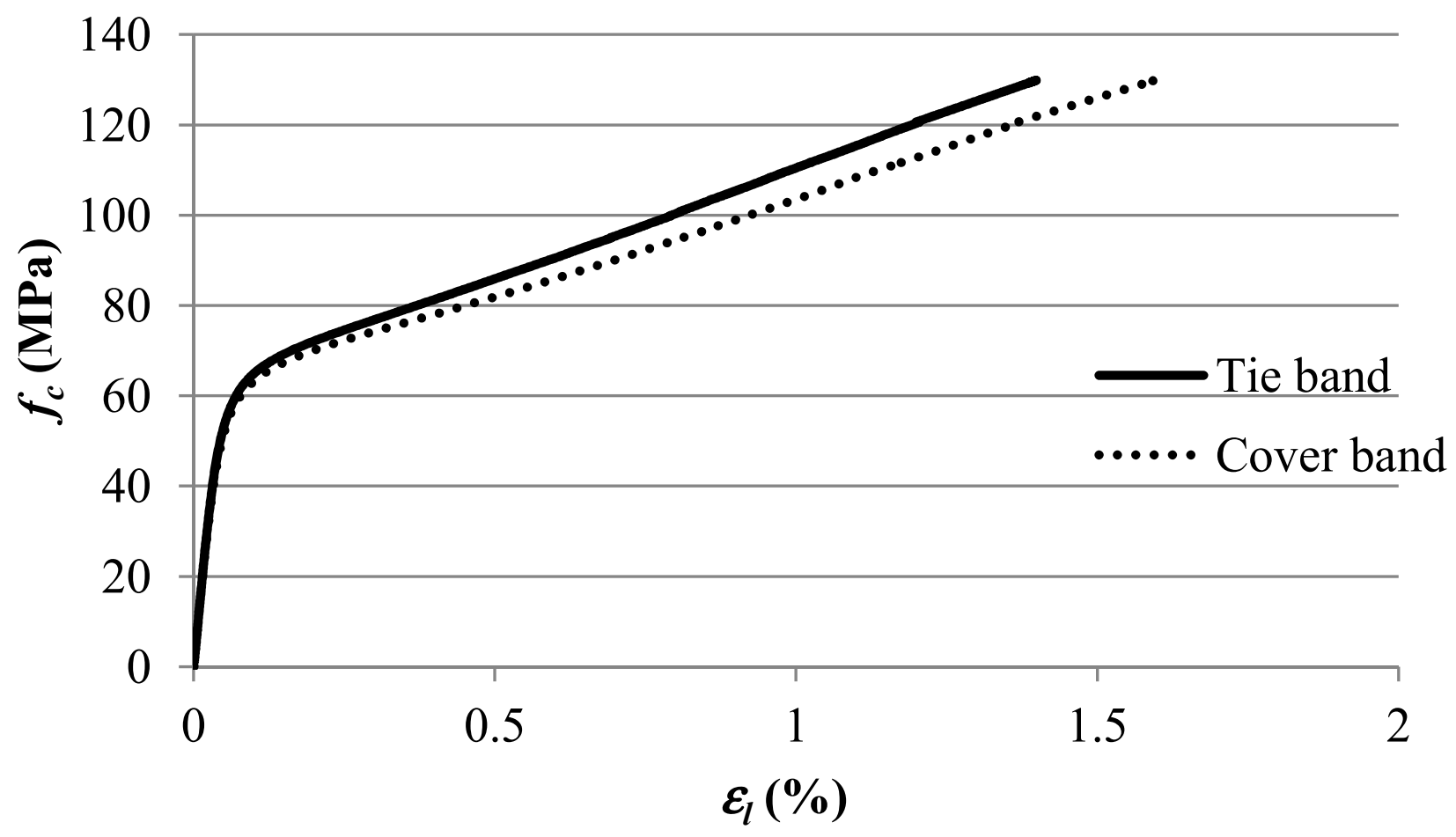

